TP Periodica Polytechnica

Chemical Engineering

58(Sup), pp. 27-33, 2014

DOI: $\underline{10.3311 / P P C h .7298}$

http://www.pp.bme.hu/ch/article/view/7298

Creative Commons Attribution (i)

RESEARCH ARTICLE

\section{Equilibrium studies of binding of cationic surfactants to sodium humate}

József Rádi / Zoltán Tóth / Aurél Marton / Rita Földényi

RECEIVEd 30 September 2012; ACcepted 27 April 2013

\section{Abstract}

The binding of the cetylpyridinium chloride surfactant (CPC) to sodium humate was studied by the method of equilibrium dialysis without the use of a background electrolyte, at $p H=7$, at $30^{\circ} \mathrm{C}$. The binding isotherm was obtained in a wide concentration range of the CPC: $6 \cdot 10^{-6}$ to $4.96 \cdot 10^{-4} \mathrm{~mol} / \mathrm{L}$. By increasing the concentration, the isotherm first tends to a saturation step which is followed by a cooperative type of behaviour. The first step was evaluated by an equation derived from the principles similar to those used in the treatment of complexation equilibria. The calculated value of the binding constant $\left(K_{X}=68\right.$ 900) and the maximum amount of the bounded CPC $\left(q_{T}=8.36 \mathrm{mmol} / \mathrm{g} C\right)$ are in a good agreement with literature data obtained by different experimental method and a different model equation.

\section{Keywords}

binding constant $\cdot$ cetylpyridinium chloride $\cdot$ equilibrium dialysis $\cdot$ humic substances

\section{József Rádi}

Department of Earth and Environmental Sciences, University of Pannonia, Veszprém, Hungary

e-mail: radijozsef@gmail.com

\section{Zoltán Tóth}

Aurél Marton

Rita Földényi

Department of Earth and Environmental Sciences, University of Pannonia, Veszprém, Hungary

\section{Introduction}

Dissolved humic substances (HSs) are widespread macromolecular, polydisperse organic colloids occurring in soils, sediments and water as a product of microbial and chemical decomposition of plant and animal residues. Their genesis, solubility, isolation, elemental composition, the investigations of molecular weight, functional groups, chemical structure (NMR, FTIR, UV-VIS, Fluorescence, MS spectra) [1-4], the interpretation of their acid-base, complexation and adsorption equilibria by various theoretical models [3], colloidal properties [4,5] as well as their environmental significance [6] are all well documented in the referred reviews and monographs of the field.

Based upon their solubility behaviour, HSs can be divided into two classes: such as the lower molecular mass fulvic acids (FAs: 500-2000 Da) and the higher molecular mass humic acids (HAs: $2 \cdot 10^{3}-10^{6} \mathrm{Da}$ ) [7]. While the FAs are soluble in water at all $\mathrm{pH}$ conditions, the HAs are soluble only in alkaline media. Their solubility and reactivity are partly due to their randomly arranged weakly acidic functional groups mostly $-\mathrm{COOH}$ and phenolic $-\mathrm{OH}$, and partly due to the presence of further hydrogen bond forming polar groups like alcoholic $-\mathrm{OH},>\mathrm{C}=\mathrm{O}$, $-\mathrm{OCH} 3,-\mathrm{NH} 2$ etc. In addition to these polar (hydrophilic) functionalities, the HS macromolecules possesses a large number of non-polar (hydrophobic) regions due to aliphatic chains and/or (poly)aromatic rings building up a 3D structure [2].

From a comparative study of a large number of IHSS standards (FAs and HAs) and samples of different terrestrial origins, it was found that the FA samples contain $12.8 \pm 1.5 \mathrm{meq} / \mathrm{g} \mathrm{C}$ carboxyl groups and $2.6 \pm 0.6 \mathrm{meq} / \mathrm{g} \mathrm{C}$ phenolic groups while the HA samples hold $8.5 \pm 0.9 \mathrm{meq} / \mathrm{g} \mathrm{C}$ carboxyl and $2.6 \pm 0.9 \mathrm{meq} / \mathrm{g} \mathrm{C}$ phenolic groups. Results were obtained by an equilibrium model based on the $\mathrm{pH}$ metric titration curve of the acids [8]. Due to this high proton binding capacity, the environmental role of HSs in controlling the speciation in the aqueous environment can not be overlooked. In a contaminated environment this speciation of the organic or inorganic xenobiotics are of considerable importance since they can have a large impact on the transport and toxicity of these pollutants (colloid facilitated transport). 
Studies in these fields are usually aimed at the quantitative characterisation of the functional groups of the HSs relating to their type, concentration, binding constants for the protons and metal ions or for the organic pollutants (xenobiotics). For the calculation of these parameters various equilibrium models have been developed over the years. In connection with the models, two specific features of the HS polyelectrolytes have to be bought into perspective.

1. In alkaline solutions HSs undergo dissociation resulting in a large number of negative charges and an electrical double layer around the molecule. The electrostatically interacting charges affect both the conformation of the HS molecules and the value of the dissociation constant. This feature is clearly revealed in the $\mathrm{pH}$ metric titrations when the data are interpreted by the usual Henderson Hasselbalch equation in terms of the degree of neutralization $(\alpha)$. The obtained $\mathrm{pH}$ vs. $-\log [\alpha /(1-\alpha)]$ functions are not straight lines (as it is experienced in the study of monoprotic acids) but rather have a curved shape [9]. As a result, the value of the calculated dissociation constant depends strongly on the degree of titration and on the ionic strength of the medium.

2. As opposed to synthetic water soluble polyelectrolytes which are built up from well defined monomeric units, HSs are, in fact, heterogeneous mixtures of fragments and/or condensation products of large biomolecules. As their conformation changes during the addition of titrant the water accessible nonpolar surface area of the HS is changing too. This phenomenon becomes especially relevant in the binding mechanism of species having hydrophobic moieties because it contributes to the overall free energy change of the binding reaction.

Considering these features, several models were developed for the interpretation of the binding of protons, metal ions and organics to the HSs. The application of models usually require a titration curve type of dataset i.e. change of the concentration of the free species (proton $\left[\mathrm{H}^{+}\right]$, metal ion $\left[\mathrm{M}^{\mathrm{n}+}\right]$ or the organics $[\mathrm{X}]$ ) as a function of the analytical concentration of the added titrant: acid or base $\left(\mathrm{c}_{\mathrm{H}}\right.$ or $\left.\mathrm{c}_{\mathrm{OH}}\right)$, metal $\left(\mathrm{c}_{\mathrm{M}}\right)$ or organics $\left(\mathrm{c}_{\mathrm{X}}\right)$ while the concentration of the macromolecular polyelectrolyte (HS), the ionic strength (I) and, if needed, the $\mathrm{pH}$ is kept constant.

The earlier discrete ligand approach that treat HS as a mixture of two or more different ligands has been replaced with a model in which it is assumed that ligand concentrations are normally distributed with respect to their $\log \mathrm{K}$ values. As a result, a class of binding sites is characterized by a Gaussian distribution curve with its mean $\operatorname{logK}$ value $(\mu)$ and a standard deviation $(\sigma)$ of the mean [10]. Binding is characterized by a large number of fitting parameters. A convenient compromise between the continuous distribution approach and the discrete models is proposed by the Windermer Humic Aqueous Models (WHAM) [3,11]. It is assumed, that there are only four types of low affinity sites and four types of high affinity sites. Proton and metal ion binding has been described by this model for several different types of HSs existing in waters sediments and soils. The non ideal competitive adsorption (NICA) [12] and the NICA - Donnan model $[13,14]$ are, in fact, a generalisation of the Hill equation relating for the binding of one species to group of binding sites with equal affinity. The model allows for proton - metal and/or metal - metal competition and includes an exponent to take care of the nonideality (cooperativity). The NICA - Donnan model defines a conceptual Donnan volume around the HSs associated with its electric double layer and defines the binding constant in terms of the concentrations inside the Donnan volume. This approach makes use of the Boltzmann distribution of the ions in the diffuse Donnan volume to relate them to the experimentally accessible bulk solution phase concentrations. Thus the binding is considered here as a result of two effects: specific (non electrostatic) interactions like hydrophobic interaction, cooperativity, heterogeneity of the HSs, (NICA) and a non-specific (electrostatic) contribution (Donnan effect). Relating to the studies of the HS - metal ion interactions the models were widely applied. For the determination of the concentration of the free metal ions methods were developed typically for the techniques of equilibrium dialysis [15], ion selective electrodes [16], voltammetry [17]. In addition to the binding of metal ions, the application of the model was extended to the binding of organics to HSs too. For the determination of the concentration of the free organics dialysis experiments [18] surfactant reversible ISE and dynamic light scattering methods were used [19-23].

Our current work has double purpose. The first is to test the applicability of a simple competitive isotherm equation derived on similar principles that are familiar in the treatment of complex equilibria [24]. In this classical approach, protons and metal ions are competing for the functional groups of the ligand while in our approach the proton and the cationic surfactant (for structure see Fig. 1.) are competing for the binding site of the HS. Our other intention is to see how the isotherm behaves in a wide range of surfactant concentrations (in the region of sub critical micelle formation concentration).

Our current work has double purpose. The first is to test the applicability of a simple competitive isotherm equation derived on similar principles that are familiar in the treatment of complex equilibria [24]. In this classical approach, protons and metal ions are competing for the functional groups of the ligand while in our approach the proton and the cationic surfactant (for structure see Fig. 1.) are competing for the binding site of the HS. Our other intention is to see how the isotherm behaves in a wide range of surfactant concentrations (in the region of sub critical micelle formation concentration).

\section{Theoretical considerations}

The humic substance is considered here as an ionized polyelectrolyte (P) which may react partly with the surfactant (X) 


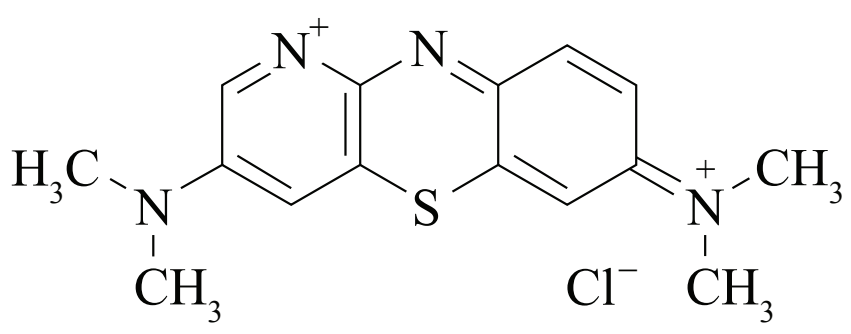

MB

Fig. 1. Structure of methylene blue (MB) and cetylpyridinium chloride (CPC)

and partly with the protons $(\mathrm{H})$ according to reactions (1) and (2), charges are omitted for simplicity:

$$
\begin{aligned}
& \mathrm{P}+\mathrm{X}=\mathrm{PX} \\
& \mathrm{P}+\mathrm{H}=\mathrm{PH} .
\end{aligned}
$$

Here P may have multiple binding sites, reactions (1) and (2) refer to one particular type of site $(i)$ with a stochiometry of 1 to 1 . The equilibrium concentration of the PX and PH species can be given by making use of the $K_{\mathrm{iX}}$ and $K_{\mathrm{iH}}$ formation (binding) constants:

$$
\begin{aligned}
& {[\mathrm{PX}]=K_{\mathrm{iX}} \cdot[\mathrm{P}] \cdot[\mathrm{X}]} \\
& {[\mathrm{PH}]=K_{\mathrm{iH}} \cdot[\mathrm{P}] \cdot[\mathrm{H}] .}
\end{aligned}
$$

Considering dilute solutions, the brackets represent relative equilibrium concentration of the species $\left(\mathrm{mol} \cdot \mathrm{L}^{-1} / 1 \mathrm{~mol} \cdot \mathrm{L}^{-1}\right.$, in principle, relative activities). If the binding constants are known then we would need three additional equations to calculate the five unknown concentrations occurring in the above equations. The supplementary equations are the mass balance equations for the polyelectrolyte $\mathrm{HS}\left(\mathrm{c}_{\mathrm{p}}, \mathrm{mg} \mathrm{C} / \mathrm{L}\right)$ and for the surfactant $\left(c_{X}, \mathrm{~mol} / \mathrm{L}\right)$ and an advantageously defined function $\left(\mathrm{q}_{\mathrm{X}}, \mathrm{mol} \mathrm{PX} / \mathrm{mg} \mathrm{C}\right)$ :

$$
\begin{aligned}
& \mathrm{c}_{\mathrm{P}}=[\mathrm{P}]+[\mathrm{PH}]+[\mathrm{PX}] \\
& \mathrm{c}_{\mathrm{X}}=[\mathrm{X}]+[\mathrm{PX}] \\
& \mathrm{q}_{\mathrm{X}}=\left(\mathrm{c}_{\mathrm{X}}-[\mathrm{X}]\right) / \mathrm{c}_{\mathrm{P}} .
\end{aligned}
$$

Since in a given experiment, the value of $c_{X}$ and $c_{P}$ are known and $[X]$ is measured, therefore $\mathrm{q}_{\mathrm{X}}$ is experimentally accessible. Using equs.(3)-(7) the following relationship can be derived:

$$
q_{X}=\frac{K_{i X} \cdot[X]}{1+K_{i H} \cdot[H]+K_{i X} \cdot[X]} .
$$

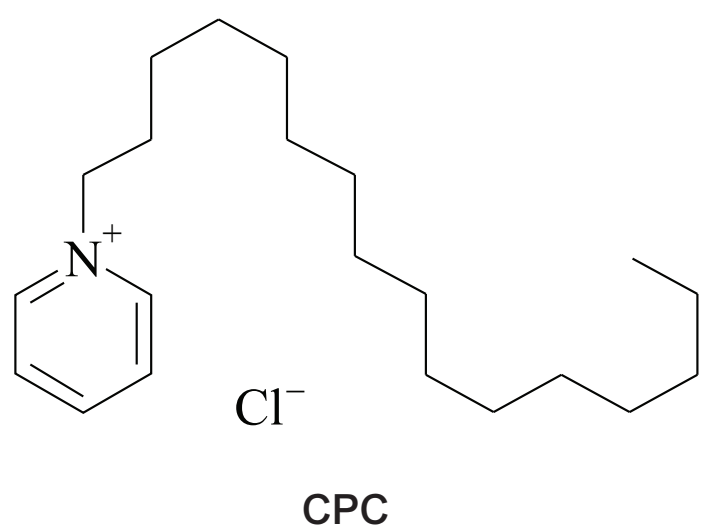

Equ.(8) is essentially the local binding isotherm of $\mathrm{X}$ for the site characterized by $\mathrm{K}_{\mathrm{i}}$. If the total amount of surfactant that can bind is $q_{\mathrm{T}}$ then the overall binding isotherm:

$$
\mathrm{q}_{\mathrm{X}}=\sum_{\mathrm{i}} \frac{\mathrm{q}_{\mathrm{T}} \cdot \mathrm{K}_{\mathrm{iX}} \cdot[\mathrm{X}]}{1+\mathrm{K}_{\mathrm{iH}} \cdot[\mathrm{H}]+\mathrm{K}_{\mathrm{iX}} \cdot[\mathrm{X}]}
$$

Equ.(9) yields the bounded mol of X/gram carbon ([PX]/g C) as a function of $\mathrm{pH}$ and the concentration of the surfactant. If there is only one type of site on the HS then $i=1$, and further on, the $\mathrm{pH}$ kept constant, then equ.(9) reduces to the Langmuir equation. From the $\mathrm{q}_{\mathrm{X}}$ vs. $[\mathrm{X}]$ plot the value of the binding constant can be calculated (the plot saturation behaviour as the concentration of $\mathrm{X}$ increases). At an arbitrary $\mathrm{pH}$ the obtained $\mathrm{K}_{\mathrm{iX}}$ value is, in fact, an apparent binding constant $\left(\mathrm{K}_{\mathrm{iX}}{ }^{\prime}\right)$ which is related to $\mathrm{K}_{\mathrm{ix}}$ by the protonation side reaction coefficient, $\alpha_{\mathrm{P}(\mathrm{H})}$, of the polyelectrolyte: $\mathrm{K}_{\mathrm{iX}}{ }^{\prime}=\mathrm{K}_{\mathrm{iX}} \cdot\left(\alpha_{\mathrm{P}(\mathrm{H})}\right)^{-1}$. If it is assumed e.g. that the carboxyl group of the HS polyelectrolyte has the same protonation constant as that of the acetate ion $\left(\mathrm{K}_{\mathrm{Ac}}=10^{4.6}\right)$ then: $\alpha_{\mathrm{P}(\mathrm{H})}=1+\mathrm{K}_{\mathrm{Ac}} \cdot[\mathrm{H}]$. At $\mathrm{pH}=7, \quad \alpha_{\mathrm{P}(\mathrm{H})}=1+10^{4.6} \cdot 10^{-7} \sim 1$ with a good approximation. Consequently, at $\mathrm{pH} 7$ the calculated apparent constant would be equal to the real binding constant. Investigation of equ.(9) leads directly to the same conclusion because the second term of the denominator $\left(10^{4.6} \cdot 10^{-7}\right)$ is negligible as compared to 1 .

\section{Experimental}

The surfactant - sodium humate binding reactions were studied by the method of equilibrium dialysis (ED). Three kinds of experiments were made. The first is meant to study the required time for the equilibration through the dialysis membrane. Here methylene blue was used as an easily measurable test compound. The second experiment was concerned with the adsorption of the surfactant on the surface of the membrane. Results are used for correction of the equilibrium concentration data obtained in the third type of experiment which was, in fact, the study of the actual binding equilibrium. The first two 
experiments were necessary because there were no information available for the behaviour of the applied cellulose membrane.

\subsection{Materials}

Methylene blue (MB) (Scharlau, Spain) is a cationic dye (Fig. 1.) and is used here as a model compound to follow the attainment of the state of equilibrium in ED experiments.

Cetylpyridinium chloride (CPC) (Sigma Aldrich Co., EU) is a surfactant (Fig. 1.) used as a disinfecting additive in medicines and cosmetics. It has a permanent positive charge due to the quaternary nitrogen of the $\mathrm{N}$-alkyl substituted pyridine ring.

Sodium humate (Carl Roth, Karlsruhe, Germany) was selected for our studies. Determination of the elemental composition by the Carlo-Erba EA-1108 analyser (at $1020^{\circ} \mathrm{C}$ ) yielded the following results: $\mathrm{C} \%=44.74, \mathrm{H} \%=4.07, \mathrm{~N} \%=1.16, \mathrm{~S} \%=2.08$, ash content $47.3 \%$ (data are referred to dry Na-humate). Since a considerable part of the oxygen is converted mostly to $\mathrm{Na}_{2} \mathrm{O}$ of the ash, its percentage can not be estimated. Lower molecular mass components of the sample were removed by dialysing the sodium humate solution using an artificial intestine bag. Soaking was continued until the total organic carbon (TOC) and the photometric measurements (at $254 \mathrm{~nm}$ ) indicated the absent of organics in the external solution.

\subsection{Equilibrium dialysis}

For our equilibrium studies dedicated dialyser equipment (Spectrum Laboratories Ltd.) was used. The equipment contains 20 Teflon cells each of which has two compartments (4-4 mL) separated by a membrane disc (diameter: $47 \mathrm{~mm}$ ). The half cells have holes for addition of solutions and for samplings. The loaded cells were assembled into a compact rotating block of the equilibrium dialyser thermostated at $30^{\circ} \mathrm{C}$ by a water bath (MLW UH Thermostat). The applied membrane was a cellulose membrane (Kelly 2000 Zrt., Hungary). In order to remove the organic preservatives from the membrane it was pretreated by soaking it for 2 hours and rinsing with distilled water. Soaking was repeated until the TOC and the photometric measurements (at $254 \mathrm{~nm}$ ) indicated the absence of organics.

The ED equipment was used to follow the attainment of equilibrium through the membrane by filling the MB test compound in one half cell and water in the other half cell. From time to time, samples were taken from both cells and were analysed for the dye by UV-VIS.

The permeability of the membrane for the CPC and for the pretreated humate was also studied by using the above analytical methods. Experiments proved that the CPC was freely distributing between the two half cells while the pretreated humate was practically rejected. The membrane proved, therefore, to be ideal for the study of the humate- CPC interactions.

For the humic - CPC binding experiments one of the compartment was filled with the sodium humate. Its concentration was maintained at a constant level of $c_{\mathrm{P}}=18.19 \mathrm{mg} \mathrm{C} / \mathrm{L}$.
The other cell was filled with a solution of the surfactant where the concentration of the CPC $\left(c_{\mathrm{X}}\right)$ was varied from $6 \cdot 10^{-6}$ to $4.96 \cdot 10^{-4} \mathrm{~mol} / \mathrm{L}$. In all experiments the $\mathrm{pH}$ of the solutions were kept at a constant value by adding a small amount of $0.1 \mathrm{~mol} / \mathrm{L}$ $\mathrm{HCl}$ (Carlo Erba, Italy) or $0.1 \mathrm{~mol} / \mathrm{L} \mathrm{NaOH}$ (Spectrum 3D, Hungary) until the $\mathrm{pH}$ reached 7.0. After 24 hours of equilibration, samples were taken from the humate free half cells of the ED system. Samples were analysed for the CPC by UV-VIS spectrometry and the concentration of the free CPC, $[\mathrm{X}]$ was obtained. Dialysis experiments were done in triplicate.

Calculation of the corrections. ED experiments usually need corrections for the losses of the distributing species due to adsorption on the membrane surface [25]. This phenomenon was investigated in a separate experiment. Membrane disks of known masses were placed into the ED equipment and equilibrated (on both sides) with $\mathrm{CPC}$ solutions ( $\mathrm{pH}=7.0$, at $30^{\circ} \mathrm{C}$ ). The initial concentration was changed from 0 to $2.79 \mathrm{mmol}$ $\mathrm{CPC} / \mathrm{L}$. After 24 hours of equilibration time the final concentrations were determined by spectrometry. Knowing the concentration difference between the initial and the equilibrium solutions $\left(\mathrm{c}_{0}-\mathrm{c}\right), \mathrm{mmol} / \mathrm{mL}$, and the volume of the solution $(\mathrm{V}, \mathrm{mL})$ as well as the mass of the air dry cellulose membrane $(\mathrm{m}=26.9 \mathrm{mg})$ the specific adsorbed amount (q, mmol/mg) can be calculated as: $\mathrm{q}=\left(\mathrm{c}_{0}-\mathrm{c}\right) \cdot \mathrm{V} / \mathrm{m}$.

\subsection{Analytical methods}

Methylene blue and CPC solutions. Samples taken from the half cells were analysed by using a Varian Cary 50 UVVIS photometer. Calibration curve (six points) for the methylene blue was recorded in the concentration range from 0 to $10 \mu \mathrm{mol} / \mathrm{L}$, at $\lambda=664 \mathrm{~nm}$. Calibration curve (six points) for the $\mathrm{CPC}$ was made in the concentration range from $2 \cdot 10^{-5}$ to $7 \cdot 10^{-4} \mathrm{~mol} / \mathrm{L}$, after appropriate dilution the absorbance was measured at $\lambda=259 \mathrm{~nm}$.

Sodium humate solutions. After the predialysis cleaning step, the total organic carbon content (TOC, $\mathrm{mg} \mathrm{C} / \mathrm{L}$ ) of the sodium humate solution was determined by a Thermo Electron Corporation TOC TN-1200 apparatus. It was considered important that, for sake of clarity and uniformity, all concentration data related to the sodium humate, should be expressed in terms of mg organic carbon per liter $(\mathrm{mg} \mathrm{C} / \mathrm{L})$.

\section{Results and discussion}

\subsection{Study of time of equilibration}

In order to gain knowledge on the time dependence of the diffusion controlled transmembrane processes the distribution of the MB was studied between the dye solution and water. Change of the concentration was followed on both sides of the membrane as a function of time (Fig. 2.). As expectable, the change of concentration follows an exponential pattern and after 24 hours they became equal in both compartments. As dialysis time 24 hours was selected. 


\subsection{Adsorption of CPC on cellulose membrane}

In order to avoid systematic error in the binding studies, a preliminary investigation of adsorption of the CPC on the ED membrane is necessary [25]. The calculated specific adsorbed amount $q$ (mentioned in section 3.2) is plotted as a function of concentration (Fig. 3.). Since the corrections will be needed for any concentration data occurring in the binding experiment, therefore it seemed to be convenient to fit first a Langmuir type of function (10) to the data and then use this function to calculate $\mathrm{q}$ at any value of $\mathrm{c}$.

$$
q=\left(q_{\mathrm{T}} \cdot \mathrm{a} \cdot c\right) /(1+\mathrm{a} \cdot c)
$$

Data were fitted to the above relationship by a least square procedure and the values of the fitting parameters as well as the statistical measures of the goodness fit were found as follows: $q_{\mathrm{T}}=0.0006$ and $\mathrm{a}=3.4, \mathrm{R}^{2}=0.9964, \mathrm{Chi}^{2}=2.2533 \cdot 10^{-12}$. In the actual series of the binding experiments the initial concentrations were corrected by the amount of the adsorbed CPC.

\subsection{Binding isotherm of CPC on sodium humate}

In order to obtain the binding isotherm for the humate - CPC system, first the bound amount $\left(q_{X}\right)$ has to be calculated by equ. (7): the value of the analytical concentration of CPC $\left(c_{X}\right)$ and that of the sodium humate $\left(\mathrm{c}_{\mathrm{P}}\right)$ is known and the value of the equilibrium concentration of the surfactant, $[\mathrm{X}]$ is measured (see section 3.2). The binding isotherm is obtained by plotting the calculated $q_{X}$ values as a function of $[\mathrm{X}]$ (Fig.4.).

As can be seen, the isotherm consists of two markedly different steps. In the low concentration range it follows a Langmuir type of behaviour showing saturation. The binding is governed here by the strong electrostatic interactions between the cationic $\mathrm{CPC}$ and the ionised carboxylic acid groups of the HS. The second step is supposed to occur due to the interaction between the already adsorbed CPC and the solution phase CPC molecules.

At $\mathrm{pH}=7$, the ionisation of the phenolic- $\mathrm{OH}$ groups can be neglected so there is only one type of binding site, the $\mathrm{R}-\mathrm{COO}^{-}$ group $(i=1)$. For this case equ. (9) can be given as:

$$
\mathrm{q}_{\mathrm{X}}=\frac{\mathrm{q}_{\mathrm{T}} \cdot \mathrm{K}_{\mathrm{X}} \cdot[\mathrm{X}]}{1+\mathrm{K}_{\mathrm{X}} \cdot[\mathrm{X}]}
$$

(as was discussed, at $\mathrm{pH}=7$ the second term in the denominator of equ.(9) can be neglected).

By using a least square calculation the Langmuir part of the isotherm was fitted to equ. (11) and yield the following values: $q_{T}=8.36 \mathrm{mmol} \mathrm{CPC} / \mathrm{g} \mathrm{C}$ and $\mathrm{K}_{\mathrm{X}}=68$ 900. The goodness of fit is characterized by the statistical parameters: $\mathrm{R}^{2}=0.936$, $\mathrm{Chi}^{2}=6.43 \cdot 10^{-7}$. In a generic case, the calculated value of the binding constant would be an apparent value $\left(\mathrm{K}_{\mathrm{X}}{ }^{\prime}\right)$. In our case, however, the obtained $\mathrm{K}_{\mathrm{X}}$ is the real value of the constant because there is no side reaction of the polyelectrolyte and the ionic strength is approaching to a low value $\cong 10-4$.

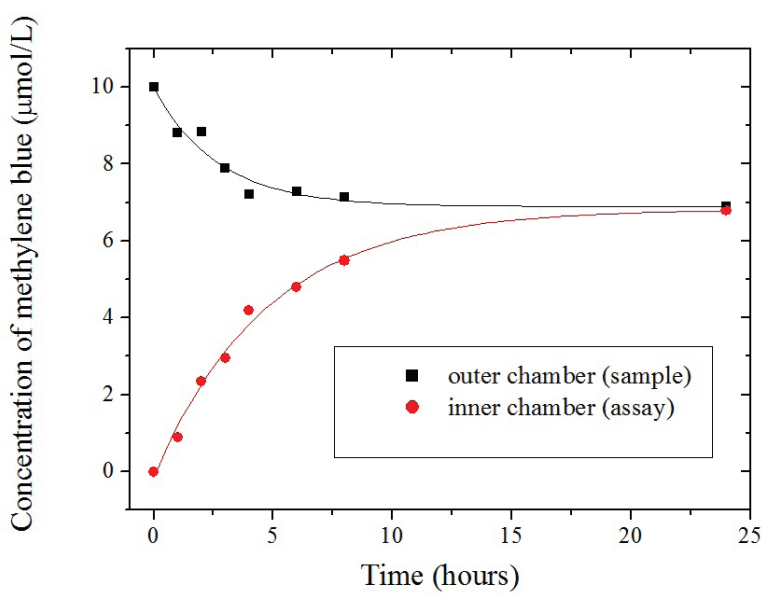

Fig. 2. Change of concentration of the MB in both half cells as a function of time

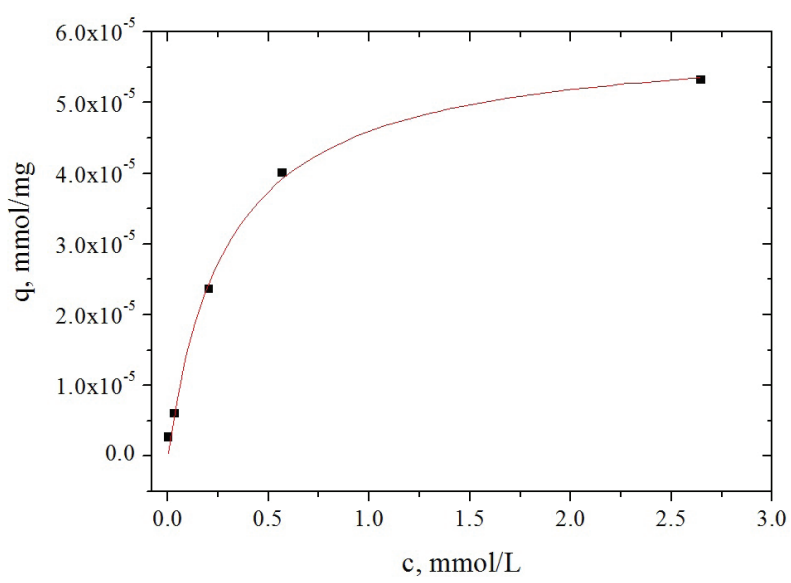

Fig. 3. Amount of CPC adsorbed $(q)$ as a function of concentration (c)

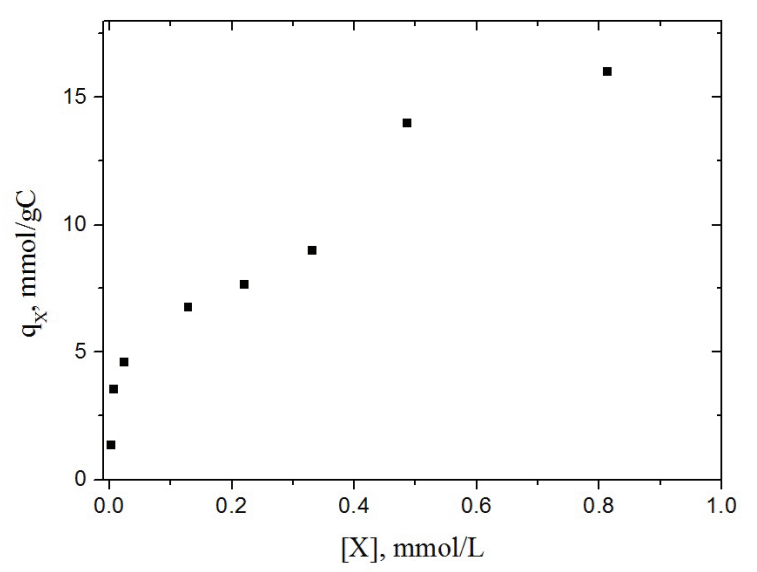

Fig. 4. Binding isotherm of $\mathrm{CPC}$ on sodium humate at $\mathrm{pH}=7$ and at $\mathrm{T}=30^{\circ} \mathrm{C}$

The study of binding of CPC to HS was also studied by Koopal et al. $[20,23]$ at $25^{\circ} \mathrm{C}$, at $\mathrm{pH}=5$ at ionic strength of 0.005 and $0.1 \mathrm{~mol} / \mathrm{L}$. The concentration of the free CPC was measured by a surfactant selective electrode. Data were evaluated 
by the monocomponent NICA equation (see equ. (9) in ref. [23]). The referred equation of [23] is similar to equ. (11) above with two differences. The binding constant is defined as an intrinsic constant that expresses the affinity between a surfactant molecule and a surface site and the $\mathrm{K}_{\mathrm{X}} \cdot[\mathrm{X}]$ term raised to the power $\mathrm{n}$ : $\left(\mathrm{K}_{\mathrm{X}} \cdot[\mathrm{X}]\right)^{\mathrm{n}}$. Here $n$ is a non-ideality parameter of the surfactant which accounts for the fact that the actual affinity of the ions for the binding site varies with the surface coverage. The obtained parameters of the two studies are compared below:

\begin{tabular}{lccccccc}
\hline & $\mathrm{HS}$ & $\begin{array}{c}\text { Temp. } \\
{ }^{\circ} \mathrm{C}\end{array}$ & $\begin{array}{c}\mathrm{I}, \\
\mathrm{mol} / \mathrm{L}\end{array}$ & $\mathrm{pH}$ & $\begin{array}{c}\mathrm{q}_{\mathrm{T}} \\
\mathrm{mmol} / \mathrm{g} \mathrm{C}\end{array}$ & $\mathrm{n}$ & $\ln K_{\mathrm{x}}$ \\
\hline $\begin{array}{l}\text { Current } \\
\text { work }\end{array}$ & Na-hum. & 30 & 0.0001 & 7.0 & 8.36 & 1 & 11.14 \\
Ref.[23] & PAHA & 25 & $\begin{array}{c}0.005, \\
0.1\end{array}$ & 5.0 & 5.65 & 1.23 & 11.408 \\
\hline
\end{tabular}

Despite of the differences in the experimental conditions of the two studies, the binding constants and the value of the $n$ parameters show a very close agreement. But the total amounts of the bound surfactant are different from those quoted from [23]. According to a recent study, however, the concentration of the $-\mathrm{COOH}$ groups of the Aldrich $\mathrm{HA}$ is $7.10 \mathrm{mmol} / \mathrm{g} \mathrm{C}$ [26] which is reasonably close to our value of $8.36 \mathrm{mmol} / \mathrm{g} \mathrm{C}$ and compares also well to the above mentioned proton binding

\section{References}

1 Stevenson F. J., Humus chemistry: genesis, composition, reactions. John Wiley \& Sons, New York (1994).

2 Ghabbor E. A., Davies G. (eds.), Humic substances: structures, models and functions. The Royal Society of Chemistry, Cambridge (2001). DOI: $\underline{10.1039 / 978184755108}$

3 Tipping E., Cation binding by humic substances. Cambridge University Press, Cambridge (2002).

4 Jones M. N., Bryan N. D., Colloidal properties of humic substances. Advances in Colloid and Interface Science, 78(1), 1-48 (1998). DOI: $10.1016 / \mathrm{S} 0001-8686(98) 00058-\mathrm{X}$

5 Tombácz E., Colloidal properties of humic acids and spontaneous changes of their colloidal state under variable solution conditions. Soil science, 164(11), 814-824 (1999).

6 Majzik A, Tombácz E., Interaction between humic acid and montmorillonite in the presence of calcium ions I. Interfacial and aqueous phase equilibria: Adsorption and complexation. Organic Geochemistry, 38(8), 1319-1329 (2007).

DOI: 10.1016/j.orggeochem.2007.04.003

7 Wershaw R. L., Aiken G. R., Molecular size and weight measurements of humic substances. in: 'Humic substances in soil, sediment and water: geochemistry, isolation, and characterization' (ed.: Aiken G. R., [et al.]) Wiley Interscience. New York, 477-492 (1985).

8 Ritchie J. D., Perdue E. M., Proton-binding study of standard and reference fulvic acids, humic acids, and natural organic matter. Geochimica et Cosmochimica Acta, 67(1), 85-96 (2003). DOI: $\underline{10.1016 / \mathrm{S} 0016-7037(02) 01044-\mathrm{X}}$ capacity of the HS carboxyl group $8.5 \pm 0.9 \mathrm{meq} / \mathrm{g} \mathrm{C}$ [8]. Both of these data indicate that the negative charges are compensated by the cationic CPC. All the further binding of CPC species is due to a different mechanism that was not considered in the derivation of equ. (9).

The reasonable agreement of the data indicates that the application of the principles used in the equilibrium of metal - ligand complexes works acceptably for the surfactant - HS binding equilibrium too. This is probably due to the apparently almost ideal behaviour of the studied system. Under diverse experimental conditions and for surfactants, the case may be quite different and the need for those non-ideality corrections, built in the NICA-Donnan model is necessary.

\section{Conclusion}

The high value of the binding constant indicates a strong association between the $\mathrm{CPC}$ and the sodium humate which affects the mobility and biodegradability of the surfactant in the environment. In an acidic media, however, the association is partially or completely broken up due to the protonation of the functional group. A practical conclusion: as compared to the high prices of the commercially available ED membranes, our experiments indicated that the cheep and disposable cellulose membrane is quite appropriate for the studies of binding in these kinds of systems.

9 Fukushima M., Tanaka S., Nakamura H., Ito S., Acid base characterization of molecular weight fractionated humic acid. Talanta, 43(3), 383-390 (1996). DOI: $\underline{10.1016 / 0039-9140(95) 01727-5}$

10 Perdue E. M., Parrish R. S., Fitting multisite binding equilibria to statistical distribution models: Turbo Pascal program for Gaussian models. Computers \& Geosciences, 13(6), 587-601 (1987). DOI: $10.1016 / 0098-3004(87) 90029-X$

11 Tipping E., Humic ion-binding model vi: an improved description of the interactions of protons and metal ions with humic substances. Aquatic Geochemistry, 4(1), 3-48 (1998). DOI: $10.1023 / \mathrm{A}: 1009627214459$

12 Benedetti M. F., Milne C. J., Kinniburgh D. G., Van Riemsdijk W. H., Koopal L. K., Metal ion binding to humic substances: application of the non-ideal competitive adsorption model. Environmental Science \& Technology, 29(2), 446-457 (1995). DOI: 10.1021/es00002a022

13 Benedetti M. F., Van Riemsdijk W. H., Koopal L. K., Humic Substances Considered as a Heterogeneous Donnan Gel Phase. Environmental Science \& Technology, 30(6), 1805-1813 (1996). DOI: $10.1021 / \mathrm{es} 950012 \mathrm{y}$

14 Koopal L. K., Saito T., Pinheiro J. P., van Riemsdijk W. H., Ion binding to natural organic matter: General considerations and the NICA-Donnan model. Colloids and Surfaces A: Physicochemical and Engineering Aspects, 265(1-3), 40-54 (2005). DOI: $\underline{10.1016 / \text { j.colsurfa.2004.11.050 }}$ 
Riemsdijk W. H., Measuring and modeling zinc and cadmium binding by humic acid. Analytical Chemistry, 74(4) 856-862 (2002). DOI: $\underline{10.1021 / \mathrm{ac} 0105080}$

16 Iglesias A., López R., Fiol S., Antelo J. M., Arce F., Analysis of copper and calcium-fulvic acid complexation and competition effects. Water Research, 37(15), 3749-3755 (2003).

DOI: $\underline{10.1016 / \mathrm{S} 0043-1354(03) 00236-7}$

17 Berbel F., Díaz-Cruz J. M., Arino C., Esteban M., Mas F., Garces J. L., Puy J., Voltammetric analysis of heterogeneity in metal ion binding by humics. Environmental Science \& Technology, 35(6), 1097-1102 (2001).

DOI: 10.1021/es000111y

18 Höllrigl-Rosta A., Vinken R., Lenz M., Schaffer A., Sorption and dialysis experiments to assess the binding of phenolic xenobiotics to dissolved organic matter in soil. Environmental Toxicology and Chemistry, 22(4), 743-752 (2003).

DOI: $10.1002 /$ etc. 5620220411

19 Koopal L. K., Goloub T. P., Davis T. A., Binding of ionic surfactants to purified humic acid. Journal of Colloid and Interface Science, 275(2), 360-367 (2004). DOI: $10.1016 /$ j.jicis.2004.02.061

20 Ishiguro M., Tan W., Koopal L. K., Binding of cationic surfactants to humic substances. Colloids and Surfaces A: Physicochemical and Engineering Aspects, 306(1-3), 29-39 (2007).

DOI: $10.1016 /$ j.colsurfa.2006.12.024
21 Yee M. M., Miyajima T., Takisawa N., Evaluation of amphiphilic properties of fulvic acid and humic acid by alkylpyridinium binding study. Colloids and Surfaces A: Physicochemical and Engineering Aspects, 272(3), 182-188 (2006).

DOI: 10.1016/j.colsurfa.2005.07.022

22 Yee M. M., Miyajima T., Takisawa N., Study of ionic surfactants binding to humic acid and fulvic acid by potentiometric titration and dynamic light scattering. Colloids and Surfaces A: Physicochemical and Engineering Aspects, 347(1-3), 128-132 (2009). DOI: $\underline{10.1016 / j . c o l s u r f a .2009 .02 .010}$

23 Ishiguro M., Koopal L. K., Predictive model of cationic surfactant binding to humic substances. Colloids and Surfaces A: Physicochemical and Engineering Aspects, 379(1-3), 70-78 (2011). DOI: $10.1016 /$ j.colsurfa.2010.11.075

24 Ringbom A., Complexation in analytical chemistry. Interscience Publishers, New York, 22-60 (1963).

25 Desoye G., Error analysis in equilibrium dialysis: evaluation of adsorption phenomena. Journal of Biochemical and Biophysical Methods, 17(1), 3-15 (1988). DOI: $10.1016 / 0165-022 X(88) 90073-5$

26 Andjelkovic T., Perovic J., Purenovic M., Blagojevic S., Nikolic R., Andjelkovic D., Bojic A., A direct potentiometric titration study of the dissociation of humic acid with selectively blocked functional groups. Eclética Química, 31(3), 39-46 (2006). DOI: $\underline{10.1590 / \mathrm{S} 0100-46702006000300005}$ 